\title{
3 A Conceptual Model for the Analysis of Site-Specific Installations
}

Keywords: spatial design, conservation, performance, actor-network theory, unruly objects, Henri Lefebvre

"The past leaves its traces; time has its own script. Yet this space is always, now and formerly, a present space." Henry Lefebvre ${ }^{1}$

In the previous chapter, I argued for a broader notion of site specificity than the connectivity between the artwork and the physical location of display. The institutional and sociocultural contexts of production and reception were also identified as parameters for a site-specific installation, leading to my suggestion to conceive site specificity as a network of site-specific functions.

In the current chapter, I develop a conceptual model for the analysis of site-specific installation artworks to understand how this network is formed and transforms over time. The model consists of two parts, one focusing on a categorization of the various functions of site specificity; the other proposing a methodology to compare successive iterations of the artwork and to analyse which "factors of influence" cause changes at a particular biographical stage.

The theoretical backbone for the first part is a theory on space offered by social geographer Henri Lefebvre (1901-1991), who published his famous book The Production of Space in 1974. Lefebvre takes the stance that spaces

1 Henri Lefebvre, The Production of Space, trans. Donald Nicholson-Smith (Oxford: Blackwell Publishing, 1991), 31.

Scholte, T., The Perpetuation of Site-Specific Installation Artworks in Museums. Staging Contemporary Art. Amsterdam: Amsterdam University Press 2022 DOI: 10.5117/9789463723763_CHO3 
are no "empty voids" that exist independently from the actions taking place. In real-life situations, people inhabit spaces and employ activities in relation to the space. In any production practice, he argues, there is a reciprocity between the physical space, the activities of people, and the symbolic or representational function of the space (for example, a museum has a different symbolic function than a factory or a living room). Lefebvre envisions the production of space as the activation of a triadic network of spatial functions, which he specifies in his triad of spatiality as the physical, social, and symbolic. After an in-depth examination of Lefebvre's theory, I propose to incorporate his views into a conceptual model for the analysis of site-specific installations by making a similar triadic distinction: the physical relationship between the artwork and its surrounding (in concept and realization), the social spaces in which the artwork is produced and experienced, and the symbolic (representational) context in which the artwork is presented.

However, to understand the influences of time and the actions applied to the artworks in museum practices, an additional approach is necessary. Hence, in the second part of the chapter, I propose to include this temporal aspect by examining the factors of influence on the artworks' transformation over time. Insights are derived from the current conservation discourse in which installation artworks are compared to a performance or live event. The analogy offers notions that are beneficial to understand the time-based ontology of contemporary artworks and to examine the causes of change in successive iterations. For the model I develop, the notion of "script" is adopted as an instrument to compare different manifestations and to understand underlying motives (by the artist and custodians). Furthermore, I translate the approach suggested by the conservation discourse, which is to "follow the actors" in daily practice, with the proposition to examine site-specific installation artworks "in action."

Both parts of my conceptual model will be applied in the examination of case examples, one directed towards a description of the network of spatial functions at distinct biographical stages (derived from Lefebvre); the other offering the analytical tools of "script" and "actor" to examine the causes of change (derived from the conservation discourse). I will argue that those two parts, which fit together and complement each other, are necessary to understand the perpetuation of site-specific installations in a museum context. The model not only offers insight into the paradoxes and dilemmas but also helps to reconsider the challenges and possibilities when re-exhibiting site-specific installations in different contexts and times. 


\section{The Conceptual Model Part 1: Triadic Model for Analysing Site Specificity}

\subsection{Introducing Henri Lefebvre's Theory on Space}

Henri Lefebvre ${ }^{2}$ (1901-1991) was a French philosopher, sociologist, and political activist, who theorized on a diversity of subjects and is best known for his engagement with social praxis and everyday life. Born and raised in Hagetmau (a rural village near the French Pyrenees), Lefebvre moved to Paris in 1919, where he studied philosophy. ${ }^{3}$ He became famous for his critical publications about societal problems, grouped together under the title The Critique of Every Day Life. ${ }^{4}$ From 1928 to 1957 , Lefebvre joined the French Communist Party. He is still considered one of the most prominent Marxist intellectuals of France, although he distanced himself from the party in later years. ${ }^{5}$ In his extensive oeuvre, Lefebvre synthesizes different disciplines and approaches of prominent thinkers of the twentieth century, looking for subjects that were disregarded in the discourse at the time. ${ }^{6}$ As his biographer Stuart Eldin states, Lefebvre was primarily interested in "the everyday, the urban, difference, social space."

Space became Lefebvre's favourite subject during the 1960s and 1970s, a period in which he experienced and criticized the influence of modern city planning; particularly in Paris, where he was involved in the 1968 protests. As he writes in the introduction to The Production of Space:

We are forever hearing about the space of this and/or the space of that: about literary space, ideological spaces, the space of the dream,

2 For an extensive reading of Lefebvre's theory of space, I refer to Edward Soja, Thirdspace: Journeys to Los Angeles and Other Real and Imaginary Spaces (Cambridge, MA: Blackwell, 1996) and Stuart Elden, Understanding Henri Lefebvre: Theory and the Possible (London: Continuum, 2004).

3 For the influence on Lefebvre's spatial theory of his youth spent in a rural area, see: Elden, Understanding Henri Lefebvre, 9.

4 Between 1947 and 1981, Henri Lefebvre published a series of articles under the title "Critique de la vie quotidienne." Republished in English translation as: Henri Lefebvre, Critique of Everyday Life, trans. John Moore and Gregory Elliott (New York: Verso Books, 2008).

5 Elden, Understanding Henri Lefebvre, 6-7.

6 For the influence of Marx's notion of "dialectic materialism" and Hegel's dialectical idealism, see: Elden, Understanding Henri Lefebvre, 15-64 and the first part of chapter 2 in the same volume, "Engaging with Philosophy," 65-69.

7 Elden, Understanding Henri Lefebvre, $1,65$. 
psychoanalytic topologies, and so on and so forth, but this thinking is never put in connection with the "actually lived space." 8

Lefebvre's goal was to bridge this gap between theory and praxis, between the spatial and social fields of interaction. His publication was highly influential for the discourse on urban planning and social geography at the end of the twentieth century, and it is still acknowledged for the way it raises awareness of "the interwoven complexity of the social, the historical, and the spatial." In developing his theory, Lefebvre drew on various disciplines, including philosophy, sociology, and human geography, and interlarded his theorems with an abundant amount of case studies. As his follower Edward Soja states, notwithstanding a "meandering and idiosyncratic style of writing," Lefebvre's ideas are still appealing to scholars, urban developers, architects, and art designers. ${ }^{10}$

As a social geographer himself, Edward Soja explains Lefebvre's theory as a critique on the traditional perspectives on space, which are based on a dual mode of thinking: one mode addressing "the concrete materiality of spatial forms, on things that can be empirically mapped"; the other concerning "re-presentations of human spatiality in mental or cognitive forms." Instead of adhering to such a binary opposition, Lefebvre envisioned a model that "draws upon the material and mental spaces of the traditional dualism but extends well beyond them in scope, substance, and meaning." ${ }^{12}$

\section{The Production of Space in Everyday Practice}

A source of inspiration for Lefebvre is Foucault's hermeneutic notion of "other spaces," or heterotopias, as he called them. ${ }^{13}$ Heterotopias are encountered

8 Henri Lefebvre first published La production de l'espace in 1974. This quote comes from the English translation: Lefebvre, Production of Space, $3^{-4}$.

9 Soja, Thirdspace, 3 .

10 Quote from Soja, Thirdspace, 8. Lefebvre's work is still part of universities' curricula in social geography and architecture. See, for example, Michael E. Leary-Owhin, ed. "Urban Planning and the Spatial Ideas of Henri Lefebvre." Urban Planning, no. 3 (June 2018). View Issue | Peer-Reviewed Open Access Journal | Cogitatio Press. In 2008, his notion of "spatial practice" was the central topic of the Dutch Artistic Research Event, organized by the Utrecht Graduate School of Visual Art and Design. See http://www.mahku.nl/mahku/philosophy.html (last accessed 23 April 2021).

11 Soja, Thirdspace, 10.

12 Soja, Thirdspace, 9, 11.

13 Foucault explains the notion of heterotopia in his famous essay "Of Other Spaces: Utopias and Heterotopias (1967)," trans. Jay Miskowiec, Architecture/Mouvement/Continuité 5 (October 1984): 46-49. 
in the cultural domain, such as a cinema or a museum, a church or a Turkish bath. According to Foucault, the spaces of heterotopia can only be fully understood if we recognize the connectivity of the actual space (the lived world) with the virtual space of the dream and the imagination (utopia). The function of heterotopias is that they overcome this dichotomy and establish a relationship between actual lived spaces and imaginary worlds, surpassing even the distance of different moments in time. According to Foucault, typical examples of heterotopias "proper to western culture of the nineteenth century" are museums and libraries, because those spaces have the capacity to enclose "in one place all times, all epochs, all forms, all tastes." ${ }^{\prime 14}$

Although Lefebvre borrows Foucault's concept of heterotopia when developing his theory, he complains that Foucault never really explains what space is. ${ }^{15}$ Quintessential to his own stance is that, whereas a comparable connectivity between real and imaginary spaces is envisioned, the focus is on the use of space or the production of space in everyday practice. To understand the production of space, Lefebvre proposes to employ a model for the analysis that envisions space as a network of productive forces - physical, social, and symbolic. It is up to the social geographer, or other social scientists for that matter, to unravel this network in concrete practices. ${ }^{16}$

I will illustrate the above by citing one of Lefebvre's own examples: a common door and its spatial functions in everyday practice. Doors can be described in a formal language - the geometrical dimensions of height, width, and depth - or in the optical terms of perception. Furthermore, doors connect spaces and allow passage when human beings step over the threshold; in fact, they become meaningful entities primarily in relation to human action. Moreover, every door has once been made, and traces of this production process may still be present when the door is in use. Finally, the door's threshold may serve a symbolic meaning, such as "crossing a threshold as analogous to passing through a lock," as Lefebvre states:

Its surrounding makes a door into an object. In conjunction with their frames, doors attain the status of works, works of a kind not far removed from pictures and mirrors. Transitional, symbolic and 
functional, the object "door" serves to bring a space, the space of a "room," say, or that of the street, to an end; and it heralds the reception to be expected in the neighbouring room, or in the house or interior that awaits. ${ }^{17}$

The tripartite dialectic suggested by Lefebvre for the analysis of space is thus geared to actual circumstances: to the physical dimensions of space, the sensory perception and practices in social life, and the symbolic meanings attributed to a particular space. If a space has a symbolic or ideological meaning, this is not because an ideology is projected onto a neutral space, but because ideologies are shaped by the space in which it is practised:

Ideologies dictate the locations of particular activities, determining that such and such a place should be sacred, for example, while some other should not, or that a temple, a palace or a church must be here, and not there. But ideologies do not produce space: rather, they are in space, and of it. ${ }^{18}$

Transposed to the current study on site-specific installation art in a museum context, the symbolic significance of a museum would thus not be projected onto the architecture of the building, but it would be shaped by $i t$, in a reciprocal interaction between the architecture, the institutional policies, the visitors' use of the space, and the wider sociocultural context in which the museum is located. This relational spatial network is subjected to continuous change; any given space can be considered the product of a transformation process within the context of the social and material world. The production of spaces should thus be studied in relation to their respective times and contexts. ${ }^{19}$

Lefebvre's theory lays the foundation for my conceptual model for sitespecific installation artworks and enables me to envision the staging or recreation of a site-specific installation as an activation of three modalities of space, attributed by Lefebvre to the physical, social, and symbolic. [See Diagram 2] 
Diagram 2 Three modalities of space: physical, social, and symbolic. $\odot$ The author. Image editing: Arienne Boelens.

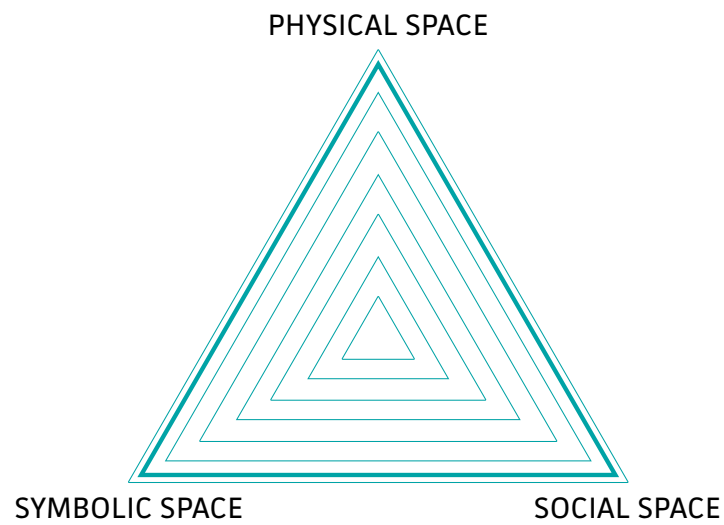

\subsection{Lefebvre's Triad of Spatiality Applied to Site-Specific Installations}

Lefebvre elaborated his thoughts on the network of spatial functions according to the following three modes: physical or "conceived" space, social or "perceived" space, and symbolic or "lived" space. ${ }^{20}$ [See Diagram 3] The first mode (conceived space) is considered the dominant and most familiar spatial function in urban planning, architecture, and other forms of design, as well as in engineering and social geography. In practice, we encounter this function in the spatial design or in abstract representations of space, as Lefebvre states - in architectural drawings, schemata of urban planning, maps, and other codes or signs. In the arts, for instance, spatial designs are expressed in sketches, technical drawings, floor plans, calculations, visualizations, or other representations of space on the basis of which works of (applied) art can be realized. The materialization of the concept into a physical space belongs to this first category as well. 
Diagram 3 Henri Lefebvre's triad of spatiality: conceived space, perceived space, lived space. $\odot$ The author. Image editing: Arienne Boelens.

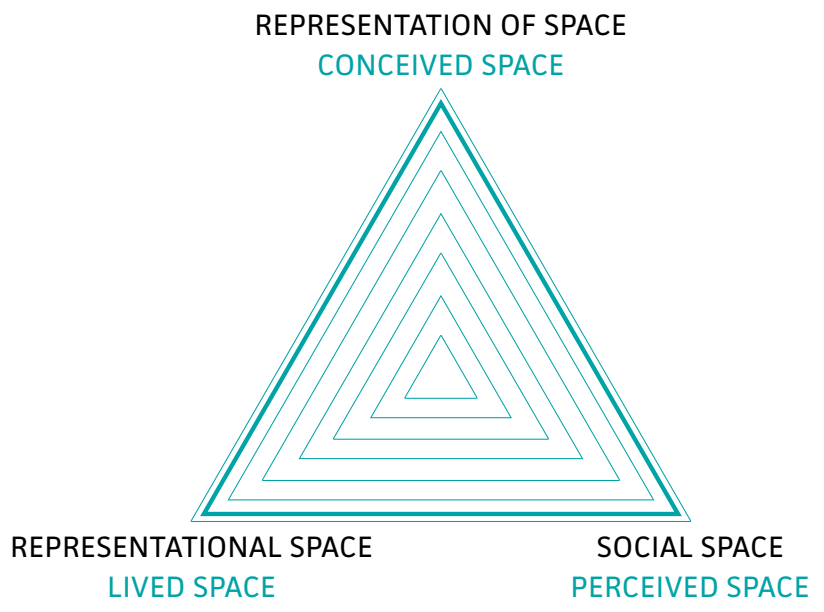

Transposed to site-specific installation art, the function of spatial design is referential for the artist's intentions regarding the spatial arrangement of the installed work in a specific context. For example, in the design process of land art projects, the spatial configuration is conceptualized by means of sketches, technical drawings and models, engineering calculations, and so forth, which serve as a "set of codes" for the realization of the work. The transformation from abstract representations to real spaces establishes, according to Lefebvre, a dialectical relationship between the formal codes and signs on the one hand, and the subjects who interpret and put them into practice on the other. ${ }^{21}$ During this process, some degree of subjectivity and contingency is unavoidable:

Representations of space are certainly abstract but they also play a part in social and political practice: established relations between objects and people in represented space are subordinate to a logic which will sooner or later break them up because of their lack of consistency. ${ }^{22}$ 
According to Lefebvre, representations of space are "relative and in the process of change," meaning that representations of a spatial design cannot be separated from the other modes of space: the social (or "perceived") and the symbolic (or "lived") space. ${ }^{23}$

In regard to the conceptual model for site-specific installations, this underscores the fact that the intended spatial design, in principle, can deviate from the materialized iteration of the work. Following Lefebvre, spatial configurations will always diverge from the plan to a certain extent, due to influences of the social and symbolic functions of space. Over the course of time, tensions between the three spatial modes might easily occur - in the case of site-specific installation artworks, sometimes with far-reaching effects on the form, function, and experience of the work of art.

Artists working with site specificity do not always follow a practice of coded representations that precede the realization of the work. In the discussion of site-specific installation art in chapter 2, I mentioned Robert Morris and Richard Serra as two artists who preferred to improvise during their performances and their realizations of site-specific installations. They discovered a working space "spontaneously" through bodily movements and handling of the material; they defined the spatial configuration of their installations "on the spot." Serra, for example, performed the Splash pieces from memory and embodied his know-how of the materials' behaviour into his actions of splashing the lead into the space. Hence, each performance established a site-specific relationship between the materials and their physical form, the spatial qualities of the room, and the artist's own body. This way, different manifestations could crystallize out of one concept, as Serra states: "Even if you try to do it [in the same way], you invariably make something else." ${ }^{24}$

The second function distinguished by Lefebvre is the "perceived space" or social space. This mode coincides with the practices employed in a given space, either by individuals or by a social group, while the indicator "perceived" refers to the conscious and unconscious ways in which spaces are being used or inhabited, and thereby influence the production process. The social or perceived space relates directly to everyday spaces where human labour, individual perception, and collective practices take place. For example, the spaces of factories, offices, schools, public transport, or

24 See, for example, an Interview with Richard Serra explaining the realization of his Splash Pieces, SFMOMA, published 23 March 2011, https://www.youtube.com/watch?v=LjvVEN2v8rY (last accessed 23 April 2021). 
museums are perceived in different ways, because people feel and behave differently in the respective places and employ different practices in them. Lefebvre emphasizes the sensorial perception of space and the use of the body in spatial practices:

Spatial practices presuppose the use of the body, [...] the use of the hands, members and sensory organs, and the gestures of work [and] activity unrelated to work. This is the realm of the perceived (the practical basis of the perception of the outside world, to put it in psychology's terms). ${ }^{25}$

Another feature of the social or perceived space is that a group of individuals may take part in the same practice, which ensures "continuity and some degree of cohesion," because the members of the group are familiar with the social patterns of that particular space and know what to do:

In terms of social space, and of each member of a given society's relationship to that space, this cohesion implies a guaranteed level of competence and a specific level of performance [original emphasis]. ${ }^{26}$

For example, the surgeons and assisting staff members in an operating room know exactly how to act and perceive the room in concord with the actions usually performed. Likewise, the conservation studio or technical department of a museum may have its own "social space," and each space will be perceived in concord with the actions usually employed in that space. Lefebvre notes that the employees or users of a space preferably have a shared know-how of the expected behaviour and competences, although this cannot always be structured in words or prescribed instructions.

Social space thus remains the space of society, of social life. Man does not live by words alone; all "subjects" are situated in a space in which they must either recognize themselves or lose themselves, a space which they may both enjoy and modify. ${ }^{27}$

In this respect, it is important to note that Lefebvre developed his theory from a post-Marxist point of view. The patterns of perception and behaviour he distinguishes in the "perceived space" are understood as collective 
production practices (of material objects) or other activities of social groups in urban society. Transposed to contemporary art, it may seem inappropriate to speak of a "shared practice" or "cohesion," because each artwork needs a particular approach and standard procedures seldom apply. Yet, I would argue that the notion of the "perceived" or "social space" does apply to the museum practice, because it is an indication of the various functions and disciplines, of skills and routines, that are performed in the various departments of the organization - behind the scenes as well as front and centre. For instance, conservation ethics is an intrinsic part of daily practices, and a set of shared codes are applicable to the diverse practices of staff members in storage rooms, technical departments, administration, galleries, visitor spaces, and so forth.

An illustration of the above is the earlier discussed site-specific project and video installation they shoot horses by Phil Collins. [See chapter 2] Various moments of spatial practices can be identified in the biography of this work. For example, during the original film shooting in the dance hall of Ramallah, there was a shared spatial practice among the volunteers; as a collective, they created a social space of dancing and stopped their movements during the calls for prayer. Later on, when the artwork entered the museum collection, the original footage was adjusted to the spatial and temporal conditions of the Tate Modern. The know-how and daily routines of staff members in the museum's technical department guaranteed the necessary adjustments of the raw footage to museum standards, not least to accommodate the installation to a gallery space and the opening hours of the museum. Finally, a spatial trajectory for they shoot horses was designed by the exhibition designers, who created a social space for the visitor's perception of the artwork. Underneath those various spatial practices, there was - at least to some degree - a consensus about what usually happens in the respective spaces of production, postproduction, and reception of the work of art.

As we have seen above, Lefebvre assumes that individuals and social groups have the potential to modify social space. Hence, individual perception is not completely disregarded, despite Lefebvre's emphasis on social space. But when I use the terms "spatial practice" or "social space" in the context of the conceptual model, I mean to say that, throughout successive biographical stages of the artwork, certain spaces may provoke certain activities while, conversely, certain actions can only take place in particular spaces; in this case, referring to the modification of the footage in the technical studio, the dancing in the dance hall, or people visiting the installed artwork in the museum's gallery space. 
The third mode introduced by Lefebvre is the "lived space" or representational space (not to be confused with "representation of space"). Every space, he states, carries a symbolic or cultural meaning for its "inhabitants" and "users," and represents a specific set of sociocultural values.

Representational space is alive: it speaks. It has an affective kernel or centre: Ego, bed, bedroom, dwelling, house; or: square, church, graveyard. It embraces the loci of passion, of action and of lived situations, and thus immediately implies time. Consequently it may be qualified in various ways: it may be directional, situational or relational, because it is essentially qualitative, fluid and dynamic. ${ }^{28}$

The lived space is variable, because ideologies and value system change over time. As mentioned in my introduction to Lefebvre's theory, ideologies and value systems may leave their imprint on any kind of spatial configuration, but they are also shaped by them. The symbolic meaning of a burial ritual, for example, is shaped by a pattern of gravestones, pathways, and trees in a graveyard; likewise, the symbolic value of a museum visit is shaped by the architectural structure of the exhibition rooms, education spaces, museum entrance, cafeteria, and so forth, as much as by the collection of artworks on display. All such spaces carry their own symbolic meaning of pleasure, reflection, education, socializing, and so on. Lived spaces are thus a combination of actual and symbolic (representational) space, both abstract and concrete and, as Lefebvre states, "need obey no rules of consistency or cohesiveness." ${ }^{29}$ In his discussion of representational space, Lefebvre refers to "the clandestine or underground side of social life, as also to art." ${ }^{\circ}$ Although the juxtaposition of the "underground side of social life" and "art" may give rise to different interpretations, in this context, Lefebvre indicates that in art, the imagination is still "free to play" with the spatial codes, making symbolic use of them and at the same time changing them..$^{31}$

Lefebvre's specification of representational space can be attributed to museum spaces in terms of a set of values, represented by the museum building as well as by the institutional philosophy and organizational principles. Even though Lefebvre developed his spatial theory several 
decades ago, his stance is still valid today and even gains significance in relation to recent research into the perpetuation of transformative and evanescent art in the contemporary art museum. With his term "unruly object," Fernando Domínguez Rubio (briefly introduced in chapter 1) provides insight into how these kind of works challenge institutional practices, boundaries, and control mechanisms that usually apply to more traditional - "docile" - artworks. His investigation focuses on how these objects play a generative role in which new practices, relations, and boundaries are formed:

In practical terms, unruly objects can be identified as those artworks that behave as variable rather than stable, elusive rather than classifiable, and unwieldy rather than portable [original emphasis]. [...] They are typically describes as "problems," "disruptions," "glitches," "challenges" that need to be fixed or solved. They are seen as those artworks that need to be transformed into docile objects. However, and this is perhaps their most distinctive feature, this transformation cannot be accomplished without altering the relations and practices wherein they inserted. Unruly objects, therefore, are characterized by the creation of organizational and institutional discontinuities that disrupt the production and sustenance of the processes whereby social practices, classifications, boundaries, and meanings are standardized and acquire their taken-for-granted nature. For this reason, unruly objects can be described as vectors of institutional and cultural change: as elements that require creative adaptations and negotiations, and the shifting of positions and boundaries around them..$^{2}$

In contrast to the stance taken by Miwon Kwon that acquisitions of sitespecific installation artworks, especially during the 199os, result from a desire to "control" the avant-garde, Domínguez Rubio highlights the inherent force these artworks possess to change institutional policies and strategies. This kind of dynamic interaction between art and the institution would, in Lefebvrian terminology, take place in the "lived space" or representational space.

It is worth reconsidering the triangular relationship between the artist, artwork, and institution with an eye to the function of lived space. Recent years have shown remarkable shifts in the representational spaces of 
museums: numerous renovations have been executed and spectacular museum buildings and annexes have been designed. This intense building activity was juxtaposed by a new take on exhibition narratives and demonstrated a renewed ambition of museums to play an active societal role. The architectural structure gives expression to new ideals by giving more room to social spaces, such as public entrances, café's, education rooms, and museum shops..$^{33}$ The curatorial interest of inviting artists to create site-specific installation artworks for museum spaces can be understood in the same light: a current emphasis on representational space.

During the late 1960 os and early 1970s, there was a similar focus on representational space when artists of the avant-garde effectuated a change in the administration of contemporary art museums. Vanguard artists (such as Allan Kaprow) rejected the representational function of the white cube gallery at first, because it was considered a representation of the commodification and "depersonalization" of art. Gradually, however, the same artists often created site-specific installations for museum galleries and agreed to the acquisition and re-exhibition of their work. This shift in practice can be explained as a transition of the museum's former representational space to a place for experiment (partly incited by the artists themselves, but even more so by energetic, visionary museum curators), changing the practice and codes of the gallery space. From a "neutral space," the galleries transformed into a "lived environment," where the artists became the "new inhabitants" of spaces that had formerly been solely the domain of museum directors, curators, and managerial staff.

\section{The Influence of Time and the Triad of Spatiality}

Lefebvre's three modes of space can be reformulated for the description of site-specific installation artworks as follows: the designed space of the artwork in connection to the spatial surrounding (coded and concrete), the social spaces of production (processes and action), and the representational space of the exhibition context (symbolic and "lived"). Based on these building blocks, the model takes shape with a first set of parameters that enable

33 See, for example, Dorus Hoebink, "The Museum as a Social Performance," in Metamorphosis. The Transformation of Dutch Museums, ed. Job Roos, Dorus Hoebink, and Arjan Kok (Delft: TU Delft - Heritage \& Architecture, 2019), 19-23. 
the conceptualization of site specificity and the description of the artwork's spatial functions across biographical stages.

At the heart of Lefebvre's model is the idea that space and time are inseparable. He argues that the production of space is anchored in a specific moment and, at the same time, is interlaced with historical traces that are left behind - or, to put it in his words, traces "inscribed" into the space:

The past leaves its traces; time has its own script. Yet this space is always, now and formerly, a present space, given as an immediate whole, complete with its associations and connections in their actuality. ${ }^{34}$

Elaborating on Lefebvre's statement, the idea takes root that a work's site specificity is produced in the actualization of the network of spatial functions (physical, social, and symbolic). In accord with the "associations and connections" of the actual site, certain spatial functions may be reinvigorated, while others may be disregarded or may have been lost altogether over time.

Furthermore, Lefebvre's collocation of past and present, supports the notion that whereas each iteration of a site-specific installation is rooted in the actuality, the work's display can bear material or immaterial traces of previous manifestations. In other words, since space and time are inseparable entities in this model, we can envision that site specificity evolves over time and takes into account that each iteration is a unique, site-specific manifestation of the work. [See Diagram 4]

The above insights about space and time, derived from Henri Lefebvre, are beneficial to the understanding of the ontology and transformative nature of site-specific installation artworks. However, they do not explain how the series of actions applied to the artwork throughout its biography influence the shifts of functions within the spatial network. In the actual practices of conservation and curation, the artwork's site specificity in a museum context is redefined again and again. Hence, to truly understand the challenges and possibilities these artworks pose to the institutions, an additional element of the model is needed - an analytical toolbox to identify the actors involved in the museum's strategies and practices, as well as the underlying "scripts" steering their decisions.

As a first step, an analogy will be drawn between the staging of a (sitespecific) installation artwork and the execution of a musical performance

Hoebink, “The Museum as a Social Performance," 36. Original emphasis. 
Diagram 4 Lefebvre's triad of spatiality transposed to site-specific installation artworks. Time influences variations in the spatial network. $\odot$ The author. Image editing: Arienne Boelens.

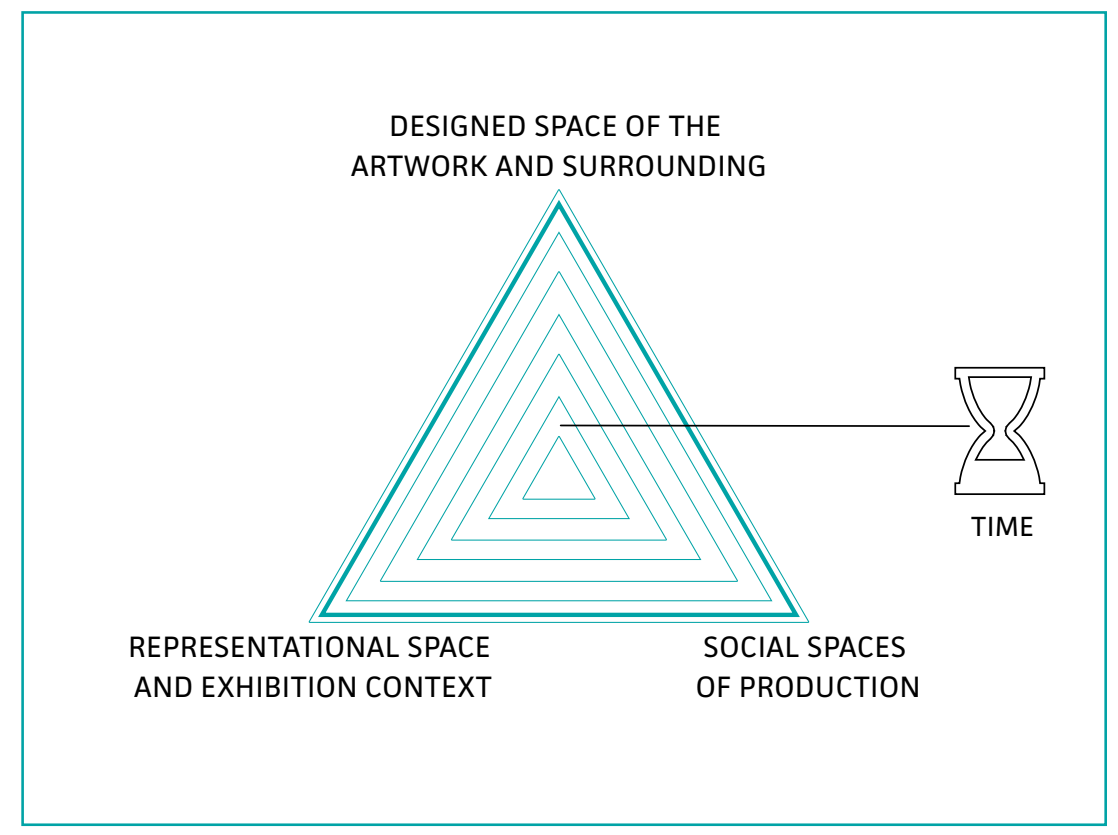

or a theatrical play. Such a comparison between two different art forms is not uncommon in the field of the humanities in general and contemporary art conservation in particular. I will start my argument with a general introduction on "performance" as an analytical tool and then zoom in on the notion of "performativity" in conservation studies.

\subsection{Analysing Cultural Phenomena "as Performance"}

The idea that cultural phenomena can be analysed as if they are performances originates from the so-called performative turn in the mid twentieth century. In 1955, the British philosopher of language J. L. Austin (1911-1960) coined the term "performativity" (1955) for speech acts. ${ }^{35}$ Austin took a stance against the prevailed, positivist claim in linguistics that utterances declare 
something as either true or false. He contended that certain utterances are not referential or descriptive but an act in themselves, like with a wedding ceremony. When a person says, "I take this woman as my lawful wedded wife," there is no reference made to a past or future action; it is an act in the here and now, changing reality at the moment of speaking. ${ }^{36}$ Austin attributed the notion of speech act only to language in real-life situations, but his ideas have been widely adopted in the social sciences and from the 1990s onwards; his views have become influential in the study of human culture in general.

Based on Austin's notion of performativity, performance scholar Richard Schechner states that any cultural manifestation can be studied in analogy with the performance arts. ${ }^{37}$ In classic theatre, the stage "frames" the action and draws a dividing line between the performance and the audience, between the "make-believe world" of the performance and everyday reality. ${ }^{3}$ However, with the 1960 s credo to fuse art with life, such traditional boundaries faded, and the "performative" has permeated contemporary cultural practice ever since. Schechner suggests that even works that are not performances in the classical sense can be analysed "as if" they were performances, provided that the manifestation is framed by the co-ordinates of space and time. ${ }^{39}$ Schechner deems visual arts and architecture suitable phenomena for this approach, because he does not consider them as "things" or "objects" in themselves, "but as players in ongoing relationships, that is 'as' performances." ${ }^{20}$ In this analysis, the focus is on a mutual comparison of manifestations that belong to the same category of work, which means he studies them "in process, and as they change over time."41

Schechner's viewpoints are relevant to the current research, because they emphasize the possibility of comparing and analysing site-specific installation artworks as a succession of iterations. By examining their "performance" in concrete circumstances, it may become feasible to discern patterns in their biographies and the causes of continuation and change, which relate to the questions posed in the first chapter of this book. First and foremost, however,

Stanford Encyclopedia of Philosophy, https://plato.stanford.edu/entries/austin-jl/ (last accessed 23 April 2021).

36 For Austin's influence on performance studies, see: Richard Schechner, Performance Studies: An Introduction (third edition) (London: Routledge, 2013), 123.

37 Schechner, Performance Studies, 28-51.

38 Schechner, Performance Studies, 42-43.

39 Schechner, Performance Studies, 38.

40 Schechner, Performance Studies, 2.

41 Schechner, Performance Studies, 48. 
a consistent set of analytical tools is needed for a systematic comparison. To this end, it is beneficial that the conservation discipline has developed a thorough theoretical framework over the past several years, based on the analogy between contemporary art and performance arts. In the following paragraphs, the focus shifts to the achievements in this field, offering a number of key notions that will prove to be highly beneficial for my own research.

\section{The Conceptual Model Part 2: Analysing Successive Iterations of Site-Specific Installation Artworks}

\subsection{Looking through the Lens of Conservation: Performativity of Site-Specific Installation Artworks}

In reaction to the many challenges posed by new art forms such as media art and installation art, conservators and curators have developed an entirely new set of theories and practices over the past two decades. One pivotal insight is that theory develops alongside practice, foregrounding the importance of communication with the artists or their representatives. Another one is the awareness that, in theory and practice, a (self-)reflective attitude is essential, given the transient nature of contemporary art. "Managing change" is an epithet that binds many contemporary artworks, as they are often intentionally made of temporary or ephemeral materials, and hence pose rigorous questions in respect to their reinstallation. ${ }^{42}$ In

42 For the discourse on managing change the following readings (among others), see: Hanna Hölling, "The Technique of Conservation: On Realms of Theory and Culture Practice," Journal of the Institute of Conservation 40, no. 2 (2017): 87-96; Vivian van Saaze, Installation Art and the Museum: Presentation and Conservation of Changing Artworks (Amsterdam: Amsterdam University Press, 2013), 22-23; Salvador Muňoz Vinas, "The Artwork that Became a Symbol of Itself: Reflections on the Conservation of Modern Art," in Theory and Practice in the Conservation of Modern and Contemporary Art: Reflections on the Roots and Perspectives, eds. Urusla Schaedler-Saub and Angela Weyer (London: Archetype Publishers, 2010), 12-17; Simon Cane, "Why Do We Conserve? Developing Understanding of Conservation as a Cultural Construct," in Conservation Principles, Dilemmas and Uncomfortable Truths, ed. Alison Richmond and Alison Bracker (Oxford: Elsevier, 2009), 164; Pip Laurenson, "Authenticity, Change and Loss in the Conservation of Time based Media," Tate Papers (Autumn 20o6), 6; Pip Laurenson, “The Management of Display Equipment in Time-Based Media Installations," in Modern Art, New Museums, ed. Roy Ashok and Perry Smith (Bilbao: The International Institute for Conservation of Historic and Artistic Works, 2004), 49-52; Glenn Wharton, "The Challenges of Conserving Contemporary Art," in Collecting the New: Museums and Contemporary Art, ed. Bruce Altshuler (Princeton: Princeton University Press, 2005), 174-176; Renée van de Vall, Hanna Hölling, Tatja Scholte, and Sanneke Stigter, "Reflections 
the early 200os, the focus shifted from safeguarding the artwork's physical constituents to the question what a transient artwork should do - or how the artwork is supposed to behave - given the ephemerality of its material composition. The primary source of information in this respect is the artist, although artist's assistants, gallerists, and custodians who are concerned with the perpetuation of the work may represent the artist in their attempt to decipher the artwork's "behaviour."

This notion was first developed by the Variable Media Initiative (founded by a group of museum professionals and media scholars) with their statement that artworks can be defined independently from the material composition or media of which they are composed. ${ }^{43}$ The Variable Media Initiative put the primary focus on the installation or "performance" of the artwork, in which it reveals its behaviour in actual circumstances. A qualification for an appropriate reinstallation is whether the conservator can identify the intended behaviour of the artwork, which is often indicated as the "ideal state." Crucial information can be obtained by consulting the artist or others who are knowledgeable about the composition and meaning of the work. ${ }^{44}$

Time-based media art conservator and scholar Pip Laurenson elaborates on this view in her seminal article "Authenticity, Change and Loss in the Conservation of Time-Based Media Installations." ${ }^{25}$ Focusing on time-based (media) artworks, Laurenson suggests comparing an installation with the performance of a piece of music or theatre. Time-based (media) artworks, she argues, can be positioned "on the ontological continuum somewhere between performance and sculpture," and can therefore be considered as "installed events" rather than as art objects that derive their meaning from material authenticity. ${ }^{46}$ Arguably, the object-centred paradigm, as usually

on a Biographical Approach," Preprints ICOM Conservation Community 16 th Triennial Conference (Lisbon, 19-23 September 2011): 1-81.

43 The Variable Media Initiative was initiated and developed by the Daniel Llanglois Foundation and the Guggenheim Museum in 2003. The approach consists of a classification based on eight medium-independent behaviours of the artwork, which are summarized as: contained, installed, performed, interactive, reproduced, duplicated, encoded, and networked. The corresponding conservation strategy includes storage, reinstallation, migration, emulation, and reinterpretation. See Jon Ippolito, "Accommodating the Unpredictable: The Variable Media Questionnaire," in Permanence Through Change: The Variable Media Approach, ed. Alain Depocas (New York: Solomon Guggenheim Museum, 2003), 47-53.

44 Ippolito, "Accommodating the Unpredictable," $50-51$.

45 At the time of publication, Pip Laurenson was Head of Conservation of Tate's Time-Based Media Art Collection.

46 Laurenson, "Authenticity," 4. Due to the rapid obsolescence of media art technology, physical components of media art installations change rapidly, and artists themselves may conceive their work to exist in multiple forms. 
applied to the conservation of "traditional" art, has its pitfalls in regard to performative artworks that rely on installation strategies and the execution of the artwork in concrete circumstances of an exhibition.

Scrutinizing the ontology of these kind of works, Laurenson compares their creation and realization with the two-staged process of a music performance; the first stage is the work of the composer, who records the musical composition in a score; the second stage begins when musicians perform the notation of the score and start to play. ${ }^{47}$ Transposed to timebased (media) installations, the concept of the work could be defined by a score, while its performance is in the actual realization of the work..$^{48}$ Like in music, a gap between the score and the execution defines the ontology of time-based artworks, which implies that, in principle, different iterations can be considered genuine performances. As Laurenson explains:

\section{Performances can occur in different times and different places with different performers and still be authentic instances of that performance. In the performance of a musical work it is recognised that there is a gap between a work as represented as a score and its performance. This allows}

47 Pip Laurenson borrows this partition into two stages from Nelson Goodman, a philosopher of art who distinguishes autographic art from allographic art forms. In general, the notion of autographic arts applies to paintings or sculptures; artworks that can be identified as genuine on the basis of the artist's signature, the evidence that the work is made by its creator and not a forgery. The performance arts, on the other hand, are based on a notational system - like a music score - created during the first stage of the work and serving as a reference for its performance during the second stage. For an elaborate discussion of Laurenson's proposition and Nelson Goodman's philosophy, see: Renée van de Vall, "The Devil and the Details: On the Relevance of Conservation Practice for the Theory of Contemporary Art and Vice Versa," British Journal of Aesthetics 55, no. 3 (2015): 288-29o.

48 In the conservation literature, the preferred term for a written definition of the artwork is "score." See Laurenson, "Authenticity," 5 ff; Joanna Phillips, "New Practices of Collecting and Conserving Live Performance Art at the Guggenheim Museum," VDR Beitrage 1 (2018): 124-132; Glenn Wharton, "Reconfiguring Contemporary Art in the Museum," in Authenticity in Transition: Changing Practices in Art Making and Conservation, ed. Erma Hermens and Frances Robertson (London: Archetype Publications, 2016), 28. Sometimes, "score" and "script" are used interchangeably. For example:Julia Noordegraaf, "Documenting the Analogue Past in Marijke van Warmerdam's Film Installations," Revista de História da Arte 4 (2015): 119; Van de Vall, "The Devil and the Details," 290; Pip Laurenson and Vivian van Saaze, "Collecting Performance-Based Art: New Challenges and Shifting Perspectives," in Performativity in the Gallery: Staging Interactive Encounters, ed. Outi Remes, Laura MacCulloch, and Marika Leino (Oxford: Peter Lang, 2014), 31; Ariane Noel de Tilly, "Scripting Artworks: Studying the Socialization of Editioned Video and Film Installations” (PhD diss., University of Amsterdam, 2011), 55. 
us to speak of good and bad performances while still being able to say that a work is the same work even if badly performed. ${ }^{49}$

It is part of the profession of a conservator to be knowledgeable about the determinative properties of the artwork and to perform its reinstallation accordingly. However, unlike the paradigm of Western music on which the analogy is based, there is no conventional notational system for this purpose. Laurenson suggests that an equivalent can be found in a set of "instructions" guiding the installation process, taking into account that these instructions may be very different for individual works in form and content, and are variable in the degree of prescription. Because "two-staged" artworks depend on interpretation, it is important to know what degree of interpretation is allowed by using the indicator of "thickly" or "thinly" defined works of art..$^{0}$ If the specifications are thinly described by the artist, Laurenson observes, "the work's determinative properties are comparatively few in number and most of the qualities of a performance are aspects of the performer's interpretation." Thickly specified works, on the other hand, are "works where the artist has specified the qualities of the work and its presentation as precisely as possible." $5^{1}$ Those specifications have a more prescriptive character for the execution, allowing for a lesser degree of interpretation. Looking at the daily practice in museums, conservators and curators often determine, in consultation with the artist, what are "fixed" elements for the work's meaning and to what extent variation and interpretation are permitted or even desired.

The above viewpoints, first stipulated by Laurenson and followed by others in the conservation field, are incentives to regard site-specific installations as a two-staged process as well. Although it might be confusing regarding another use of the term "stage," employed in this study in reference to the artwork's biographical stages, this distinction seems appropriate. The first stage could be attributed to the spatial design and the artist's specification of the spatial arrangement in relation to the surrounding site. Specifying the installation to a more or lesser degree, floor plans, sketches, photographs, films of the installed work, records of the sensorial requirements, as well as guidelines for reinstallation and material-technical information, could all qualify as a set of instructions defined during the first stage. Or, to put

49 Laurenson, "Authenticity," 5.

$5^{0}$ Laurenson, "Authenticity," 5. Laurenson borrows the distinction between thinly and thickly specified works from the philosopher Stephen Davies, who developed this theory in relation to Western music.

$5^{1}$ Laurenson, "Authenticity," 5 . 
it in Lefebvrian terminology, this first stage could be the conceptual mode of the artwork's site specificity. The second stage begins when the artwork is installed in the gallery space and is perceived by the audience, which can be considered the performance of the work.

More than with installation art at large, with site-specific installations (changes in) the physical surrounding and the representational space of the museum determine the form and content of the artwork's meaning and social space of the visitor's experience. These functions - identified by Lefebvre as social space and representational space - are susceptible to the contingency of the site, which may or may not be fully incorporated into the artwork's spatial design from the beginning. Usually, there is a time gap between iterations - when the artwork is dormant in a storage room or physical constituents no longer exist; museum buildings may be renovated, museum policies may evolve, and audiences may change. The passage of time and change of site are influential factors on site-specific installations. Arguably, the differences occurring between various biographical stages - between the "conceptual" stage and the "performance" stage - may be substantial. Most of the contingencies and changes cannot be foreseen when the artist conceptualizes the work nor at the moment of its acquisition by a museum curator. In this respect, a set of instructions may steer future performances, but to reactivate the work in different circumstances, an interpretative voice regarding the entire network of spatial functions may also be necessary.

As for the conceptual model under development here, the above discussion illuminates the mutual relationship between the functions of site specificity and the factor of time. Whereas the triangular set of functions (derived from Lefebvre's theory) helps to identify the constituents of site specificity, the discourse on the conservation of contemporary art offers a model that is based on the analogy of the performance arts and enables us to understand how the artwork evolves over time.

There are a few additional comments I would like to make. The first concerns the term "performance" used in the conservation discourse, in relation to the interpretative authority of the custodians. Assuming that site-specific installations come into being through an intended "interaction" with the gallery space and other contextual elements (such as the connection with the building, the collection, the public, and the sociocultural context at large), it is likely that custodians have at least some interpretative authority in future iterations. Social and representational functions of the museum largely belong to the domain of curators and other museum professionals. Although this is not the place to examine the degree to which the interpretation of a site-specific installation artwork can and should be interpreted, I 
would like to emphasize that, somewhere during the processes and practices of reinstallation, a "reflective space" is needed in which custodians consider how the artwork should be staged from the perspective of its spatial adaptation to the actual situation and the contingencies of the site.

The second comment is a refinement in terminology, as suggested by curator and conservation scholar Tiziana Caianiello, paving the way to the next step of the model. Caianiello makes a distinction between "performance" and "staging," the latter term referring to "the process of planning $[\ldots]$, testing, and determining strategies" - that is: to decision-making and the processes and practices of the artwork's perpetuation. "Performance," on the other hand, is the term assigned to the outcome of this process "that occurs only when an installation has already been staged and is taking effect on (at least) one viewer." ${ }^{2}$ Caianiello argues for leaving aside the terms $r e$-staging and $r e$-performance, because with each instantiation, a new staging and a new performance takes place. I consider this distinction appropriate, primarily because it incorporates the experience of the work as an important parameter, and the terms staging and performance will likewise be employed in this study. ${ }^{53}$

The third comment concerns the different ways requirements for a reinstallation can be captured in a notational system, including the visualizations of an installation with photographs and videos. Images are strong markers for the performance of an installation artwork, as Martha Buskirk observes (see the introductory case of Allan Kaprow's Yard and the discussion on historical evidence in chapter 2). She acknowledges the benefits of visualization, but is also cautious about it, because iconic photographs of the first iteration frequently serve as a reference for the identity of the work and may easily turn into a guidance for future iterations. Visual material or otherwise recorded evidence may give an impression of how visitors interact with the installation, but, as Buskirk contends, documentation not only registers but also isolates a historical moment that can never be retrieved. ${ }^{54}$

52 Tiziana Caianiello, Media Art Installations: Preservation and Presentation. Materializing the Ephemeral (Berlin: Dietrich Reimer Verlag, 2013), 209.

53 For the initial occurrence, Caianiello uses the term "first staging."

54 Buskirk demonstrates this view with the example of Kaprow's Yard. Audiences that were never there can experience the artwork from photographs, showing a diversity of reinterpretations of the original manifestation over time. The downside is that "the photograph falsely locks into place a conception of the work as a single, now inaccessible moment" and that iconic photographs of the initial Happening are referential for the ideal moment of display. Martha Buskirk, Creative Enterprise: Contemporary Art Between Museum And Marketplace (International Texts in Critical Media Aesthetics. Volume 3) (New York: The Continuum International Publishing Group, 2012), 129-144. 
Following Buskirk at this point, I would say that the use of photographs poses a risk that a site-specific installation is "fixed" in its (initial) historical state, while "live elements" such as contextual relationships with the gallery space and the wider sociocultural context, including the interaction with the audience, are disregarded. This way, the installation might lose its capacity to establish a connection with the new site, while only a relic of the spatial arrangement is maintained.

Taking note of the above, it is now time for a closer examination of the instruments developed in the conservation discipline for studying the staging and performance of installation artworks, and to see how these can be integrated into the model for the analysis of successive iterations of site-specific artworks.

\subsection{Site-Specific Installations as Networks "In Action"}

The idea that contemporary artworks can be understood as heterogeneously composed networks was first introduced by conservation scholar Vivian van Saaze. In Installation Art and the Museum: Presentation and Conservation of Changing Artworks, Van Saaze proposes to study contemporary art conservation by "following the actors" of the network during practices applied to the conservation and presentation of the artwork. ${ }^{55}$ Against the background of science-and-technology studies - in particular the actor-network theory (ANT) developed by Bruno Latour and others in the 1980s - Van Saaze puts into focus the social environment of museum practices and the "productive activity" of conservation and presentation. ${ }^{56}$ Contemporary art conservation is "done" in practice, as her credo reads. By scrutinizing the network of human and nonhuman actors, insight is gained into the meaning production of the artwork and the processes of decision-making. ${ }^{57}$

It helps to analyze "art in action," and draws attention to changes, transformations, and places of friction. Such an approach allows a consideration

55 Van Saaze, Installation Art, $147 \mathrm{ff}$.

56 ANT was first developed at the Centre de Sociologie de l'Innovation of the École nationale supérieure des mines de Paris in the early 1980 s by Bruno Latour, John Law, and Michel Callon. For an introduction to ANT, see: Bruno Latour, "On Actor-Network Theory: A Few Clarifications Plus More than a Few Complications," Soziale Welt, 47 (1996): 1-16. Van Saaze explains the relevance of Latour's theory for the study of museum practices in Van Saaze, Installation Art, 146-148.

57 Van Saaze, Installation Art, 27. 
of the constituting role of the museum and a recognition of the distinction among actors which is usually overlooked..$^{8}$

One of the cornerstones of the actor-network approach is that both human beings and nonhumans can have agency. According to Latour's own observation, "An actant can literally be anything provided it is granted to be the source of an action."59 Although ANT does not say that things have the capacity to act in the same way as human beings, it suggests that things and human beings are equally important participants of a productive network - of science, art, or the social world. By examining these networks as "a continuously altering association of humans and nonhumans," the causes of action and processes of production can be analysed. ${ }^{60}$ Latour and Van Saaze both raise the point that an actor-network analysis is not something one does from an objective distance:

The key point is that every entity, including the self, society, nature, every relation, every action, can be understood as "choices" or "selection" of finer and finer embranchments going from abstract structure - actants - to concrete ones - actors. ${ }^{61}$

Being aware that the researcher becomes an actor when studying the artwork in action, I see benefits in this approach for the analysis of the processes of staging and actual manifestation of site-specific installation artworks. ${ }^{62}$ It helps to understand the complex relationships between people and things, ideas and intentions, spatial conditions and visitors' behaviour, instructions, agreements, decision-making processes, and so forth, at specific places and moments in time.

58 Van Saaze, Installation Art, 28.

59 Latour, Sociale Welt, 7. According to ANT, both human and nonhuman "actants" have agency, because they act within dynamic networks. In the study of knowledge-production processes or cultural practices, the emphasis is on a "symmetrical approach" in which human and nonhuman actants are assigned as equally productive forces. The idea is illustrated with the well-known example of the gunshot. Is the person who shoots the gun or the gun that releases the bullet responsible for the shooting? The point made by Latour here is that the origin of the action is localized both with the gun and the shooter. For actants and the example, see: Bruno Latour, Resembling the Social. An Introduction to Actor-Network Theory (Oxford: Oxford University Press, 2005), 63-70, 76 .

6 o Van Saaze, Installation Art, 148.

61 Latour, Sociale Welt, 8.

62 For the current study, this applies, for example, to the research activities carried out within museums or in collaboration with interviewees and other researchers. 
In conclusion, in addition to Lefebvre's triad of spatiality and the performance analogy, the actor-network approach paves the way to develop an analytical toolbox for a systematic analysis of successive iterations. The assumption is that site-specific installations move from one stage to another as the result of a series of decisions and activities. Looking through the lens of ANT, the premise is that both human and nonhuman actors can fulfil an active role in the reactivation of the artwork's site specificity. Moreover, Van Saaze's proposition to follow the artwork in action is beneficial for identifying what factors influence the shifts in spatial functions of the artwork over time - not least because "mapping the network of actors" can bring to light discrepancies and contradictions regarding the initial site specificity, which might be easily overlooked otherwise.

Part of this approach is to regard the "script" as an analytical tool, as I will suggest in the following paragraphs. Similar to theatre or film actors, who mostly perform a play on the basis of a script composed by the playwright, we could imagine that custodians of a site-specific installation look for an underlying script, envisioned by the artist in the creation of the work and to which they aim to respond when staging the work in a new site-specific context. It seems to be a useful notion that deserves closer examination, first by looking into ANT again, followed by a discussion of the "script" as an agent in conservation and exhibition design.

\subsection{Using the Script as an Analytical Tool}

Against the background of the actor-network theory, Madeleine Akrich and Bruno Latour elaborate on the notion of script for technological objects. ${ }^{63}$ They aim to develop a vocabulary for describing the "association" of human and nonhuman actants, which, in the case of technology, starts from the idea that these "objects" contain a "program of action" and that "things-in-use" can prescribe a specific form of action. ${ }^{64}$ For example, the heavy weight attached to a hotel key has the prescription that the guest will return the key

63 Madeleine Akrich and Bruno Latour, "A Summary of a Convenient Vocabulary for the Semiotics of Human-Nonhuman Assembles," in Shaping Technology / Building Society, ed. Wiebe E. Bijker and John Law (Cambridge, MA: The MIT Press, 1992), 259-264.

64 Akrich and Latour, "A Summary of a Convenient Vocabulary," 259-26o. 
to the front desk before leaving the hotel. Or, as philosopher of technology Peter-Paul Verbeek observes,

[a] plastic coffee cup, for instance, has the script "throw me away after use"; the cameras along many roads in the Netherlands have the script "don't drive faster than $5^{\circ} \mathrm{km} / \mathrm{h}$." Artefacts are not passive and inert entities. They actively co-shape what actors do. ${ }^{65}$

Madeleine Akrich uses the script as an analytical tool to explain why designers' intentions regarding the use and form of an object may turn out differently when the object is put into use. Designers, she states, anticipate how future users will employ the object according to a "script" or "scenario," which may include guidelines as well as the functionality and competences "inscribed" into the object by the designers. ${ }^{66}$ The projected user, however, may be quite different from the real user who acts in another context and time. To understand this diversity, Akrich points to the effectuation of the script in terms of a performance, defined by the co-ordinates of space and time:

Thus, like a film script, technical objects define a frame of action together with the actors and the space in which they are supposed to act. ${ }^{67}$

As Akrich clarifies, there is uncertainty about the user's behaviour and sometimes "devices go wrong," not in the least due to differences in cultural contexts. ${ }^{68}$ Hence, the script can be best applied to a comparison between the intended design and the actual performance of the object in more or less comparable contexts.

[the script leads us] back and forth continually between the designer's projected user and the real user [...] and provides a "key" that can be used to interpret all subsequent events. [...] Nevertheless, although users add their own interpretations, so long as the circumstances in which the device is used do not diverge too radically from those predicted by the designer,

65 Peter-Paul Verbeek, What Things Do: Philosophical Reflections on Technology, Agency, and Design (University Park, PA: Penn State University Press, 2005), 125.

66 Madeleine Akrich, “The De-scripting of Technological Objects," in Shaping Technology / Building Society, ed. Wiebe E. Bijker and John Law (Cambridge, MA: The MIT Press, 1992), 208. 67 Akrich, "De-scripting," 208.

68 Akrich, "De-scripting," 211. 
it is likely that the script will become a major element for interpreting interaction between the object and its users. ${ }^{69}$

Following the principles of ANT, such an analysis is done in writing, because language provides applicable means to describe the actual form and use of the object, as well as to reveal the designer's intentions or possible deviations from the script. Hence, as Akrich proposes, the process of de-scripting may start from observations in the here and now and then, by moving backwards and putting into words the interaction between the object, human beings, and past contexts, we return to "the world in-scribed in the object."70

Although the notion of the script, defined by Latour and Akrich for technological objects, cannot be directly applied to most contemporary artworks (given fundamental differences in the nature and function of both object categories), it seems to offer a productive approach for the analysis of different iterations of site-specific installation artworks in a museum context. That said, it is a key to the current study whether we can still speak of a similar cultural context when the artwork is relocated, a question to which I will return in my case study chapters.

\section{The Method of De-scripting}

Within the conservation field, the method of de-scripting has gained currency, as, for example, in a study on installation art by the art historian Ariane Noel de Tilly. ${ }^{71}$ She applies Akrich's method to installation artworks that appear in multiple forms while still being considered the same work of art:

[De-scripting is] going back and forth between the artist's concept and the persons interpreting the work (curators, conservators, technicians, registrars, visitors, etc.). De-scribing here would mean identifying and analyzing the interactions taking place between the artistic creation (or art object), its creator, and other mediators interacting with it. In the end, the purpose of description is to put on paper the text of what the various actors in the settings are doing to one another. ${ }^{72}$

69 Akrich, "De-scripting," 208-209, 216.

70 Akrich, "De-scripting," 208-209.

71 Ariane Noel de Tilly, "Scripting Artworks: Studying the Socialization of Editioned Video and Film Installations" (PhD diss., University of Amsterdam, 2011), 58-59.

72 Noel de Tilly, "Scripting Artworks," 59. 
Noel De Tilly suggests to make a clear distinction between the "script" (or "score") defined as a set of inscriptions and the method of de-scripting as proposed by ANT. Whereas the script can be regarded as a steering factor in the decision-making processes on which the performance of the work is executed, the method of de-scripting can be considered a tool for observation and analysis of the similarities and deviations between various iterations. ${ }^{73}$

The art of de-scripting is also a methodological instrument for a scholar in the field of art and architecture, Albena Yaneva. Similar to Noel de Tilly, the author borrows viewpoints from Latour and Akrich regarding a method for analysing the trajectories of contemporary installation artworks as well as of architectural buildings. ${ }^{74}$ In Mapping Controversies in Architecture, Yaneva examines the underlying scripts of a building, particularly at moments when controversies arise, for example, when a historic building is renewed with a modern extension or is renovated. By comparing successive architectural stages of the building, not only could the controversy be explained from the standpoints and desires of the various parties (human actors) involved, but also an analysis of "the turmoil it triggers" can demonstrate that the building itself has "particular abilities to act." 75 The causes of "turmoil" can be understood by de-scripting all human and non-human actors; in architecture, this would include the architect, the spatial design of the building, the materials applied to its structure at various historical stages, or other influential forces and events, such as "the discordant voices of its makers; of qualities and substances; of passers-by's noises; and of accidents." ${ }^{76}$

This proposed method of de-scripting the actors and agents involved in a turmoil, opens up an interesting vista for the analytical toolbox of my model, because Yaneva takes into account the entire set of relationships activated at the moment of a controversy. In the case of site-specific installation artworks, this can be interpreted as a "turmoil" arising when the connectivity between the artwork and the site is redefined - or, to reuse the words of Nick Kaye, when uncertainties arise about the "fixation" of a site-specific installation artwork in the initial or any other given context of a biographical stage. [See chapter 2] In terms of Lefebvre's triad of spatiality, uncertainties would especially arise in the functions of social and representational space, because

Noel de Tilly, "Scripting Artworks," 58-59.

74 For an elaborated case study by Yaneva concerning the process of exhibiting a complex installation artwork in a museum context and the actors involved, see: Albena Yaneva, "When a Bus Met a Museum: Following Artists, Curators and Workers in Art Installation," Museum and Society 1, no. 3 (2003): 116-131.

75 Albena Yaneva, Mapping Controversies in Architecture (London: Ashgate, 2012), 26.

76 Yaneva, Mapping Controversies, 20. 
these are particularly time-dependent. The spatial design, on the other hand, might be a relatively stable factor, provided that the artist drew up a script in the form of spatial codes (technical drawings, set of instructions for the spatial arrangement, and so on), and only as long as the surrounding space in which the artwork is staged has not changed. In general, we may conclude that, in the case of site-specific installations, many different factors and contingencies come into play, which cannot be foreseen at the moment of creation and which reveal themselves only during the act of presenting the work in a new context. Arguably, a descriptive approach for successive iterations includes a wide range of actors and factors of influence, which cannot be standardized. But the approach of de-scripting the successive stages of a site-specific installation can at least map out which actors and agents come into play and how various scripts become a productive force in the realization of the artwork at a specific site.

Looking at exhibition design and curatorship, others have argued that the script is a useful tool for analysing exhibitions as a network of relationships. For example, cultural studies scholar Julia Noordegraaf introduces in her methodological study of museum exhibitions the notion of the script "to analyse the complex relations between such diverse components as people's ideas and intentions, material objects, buildings and visitor behaviour."77 Similar to Akrich's suggestion, Noordegraaf moves back and forth between the intentions of the exhibition designers, the objects themselves, and the "imagined" users of the exhibition, the visitors:

In the case of museums, the "object" is the presentation itself, which [...] comprises the location, the architecture and layout of the building, the organisation and design of the displays and the means of visitor guidance. An analysis of the script of museum presentation can bring to the fore the set of instructions that defines the relationship between the museum and its audience..$^{8}$

In the analysis of site-specific installation artworks, the script could thus be a tool for moving back and forth between the intentions of the artist and the motives of the curator and other custodians to safeguard the artwork and reinvigorate its site-specific functions, including the conditions of the space, the routes the visitors take, and safety measures. If we focused only 
Diagram 5 Triadic model for the analysis of site-specific installation artworks with an additional toolbox of script and actors. $\odot$ The author. Image editing: Arienne Boelens.

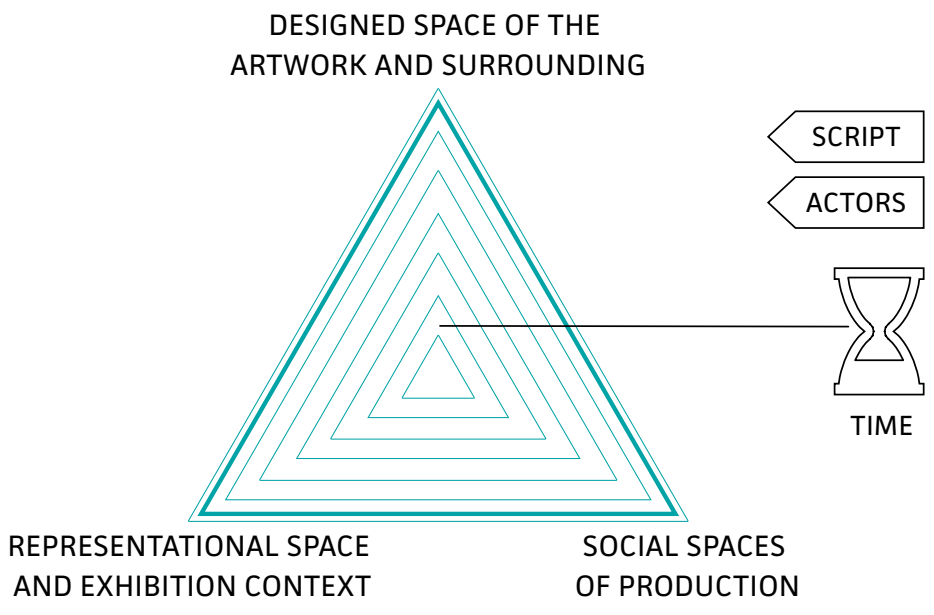

on the installation artwork itself, we might run the risk of overlooking how influential some of those seemingly insignificant actors are.

In conclusion, I propose to include an additional toolbox in the model (next to the triangular model of site specificity), consisting of an analysis of the network of actors involved and scripts employed during successive staging processes and the actual performance of the work. [See Diagram 5]

Earlier in this chapter, I adopted from the conservation discourse the idea that a script or score defines the ontology of the artwork, often in the form of a set of instructions provided by the artist for the preservation and reinstallation of the work. Thereafter, I argued that the script could also be seen as an analytical tool, opening the possibility for distinguishing the various actors and factors of influence during successive biographical stages of site-specific installations. Given the dynamics of changing contexts, it follows that the intended script cannot always be followed, and we might have to accept deviations that occur under the influence of decisions taken by others than the artist. In a museum context, the "others" are mostly the museum professionals, but gallerists or museum visitors might also turn into agents that provoke a decision, let alone the material 
and immaterial conditions that are "inscribed" into the artwork itself and the surrounding context. The toolbox of script and actors can support a description of these deviations, in particular by identifying which actors and underlying scripts are decisive in the process of staging the work in a particular context. However, as Latour and others observe, such an analysis is never a neutral exercise, and I am aware that the selection of what is described and analysed, as well as the act of de-scripting, incorporates a subjective element. However, the examination has at least some degree of objectivity in the systematic comparison of different iterations and the employment of well-described parameters, such as the proposed triangular set of site-specific functions.

Let me illustrate some of the above with a taste of what will follow in the case study chapters. A brief description of two of Richard Serra's site-specific installations will illuminate my approach of using the triad of spatiality and the analytical toolbox of script and actor. Tilted Arc (1981), discussed in the previous chapter, will be revisited from this perspective. The other example, Waxing Arcs (1980), created by Serra as a site-specific installation artwork for Museum Boijmans Van Beuningen, will show how a work's site specificity can be reactivated for a contemporary audience.

\subsection{A Short Analysis of Two Site-Specific Installations by Richard Serra}

\section{Tilted Arc Revisited}

The discussion on Tilted Arc specified that Richard Serra conceived his work as physically and conceptually rooted in the Federal Plaza. The curved Corten steel plates cutting the square in half were destined to stay in that site-specific environment forever. [Figure 5]

The spatial design (the conceived mode of the triad of spatiality) defined the dimensions and exact curves of the arc, and the Corten steel material and its finish were incorporated in this scheme. The trajectories taken by commuters to traverse the square were part of its social function, the way in which citizens experienced and "used" the artwork in their daily routines (the perceived or social space in terms of the model). As Richard Serra states, it was the "explicit intention of site-specific works to alter their contexts."79 
The artist anticipated how citizens would cross the square and navigate along the Corten steel "wall." This function can be seen as the intended outcome of a script elaborated in the functional design - the spatial arrangement and materialization of the arc. Furthermore, the Federal Plaza is a location with a special representational function (the lived space in terms of the model), because it hosts the offices of the federal government. The government commissioned the project and because of human traffic to its building, the plaza is usually a crowded space.

The "turmoil" that arose when the government proposed to relocate Tilted $A r c$ to a scenic environment outside the city can be analysed as a conflict between various scripts and actors. Serra and his protagonists claimed that the contract between the artist and the government was breached and that a proposition for relocation was an "assault on freedom of artistic expression." According to the opponents, Serra had not taken into account the social function of the plaza, and citizens reclaimed the right to use the square like before, as a social space meant for local inhabitants and employees. In this respect, the role of the federal government is interesting, because the government had installed a jury (representing the public), which had initially applauded the proposal, but turned against it during the lawsuit. ${ }^{81}$ This radical turn was unforeseen at the moment the artist developed his design. At that stage, the focus was on the spatial design and Serra's artistic views on site specificity. During the actual "performance" of Tilted Arc, however, the citizens and government put the representational function and social space of the plaza to the fore. The artwork itself was sacrificed in this process of conflicting values, following Serra's wish to adhere to the conceived mode of his spatial design. Although the artist inscribed site-specific functions to Tilted Arc, he could not foresee that such a dramatic deviation of the script would happen in later years.

In brief, three stages of Tilted Arc can be recognized: the first stage of its conception as a site-specific installation, the agreement with the government, and its realization; the second stage during the performance of the artwork in public space; and the third stage when the lawsuit marked the end of the project by means of the destruction of Tilted Arc. Perhaps, especially in the case of Titled Arc, an additional fourth stage should be acknowledged in the ongoing interest in this case example, as the discussions never came to an end, although all that remained were descriptions and a few photographs.

8o Weyergraf-Serra and Buskirk, Destruction of Tilted Arc, 69.

81 Weyergraf-Serra and Buskirk, Destruction of Tilted Arc, 68-69. 
Figure 9 Waxing Arcs (1980, second version 1999) by Richard Serra. Collection Museum Boijmans Van Beuningen, Rotterdam (MBVB). Donation: Stichting Fonds Willem van Rede. Photo: Nieuwe Beeldenmakers, Ernie Buts. Courtesy photographer and MBVB. @ c/o Pictoright Amsterdam.

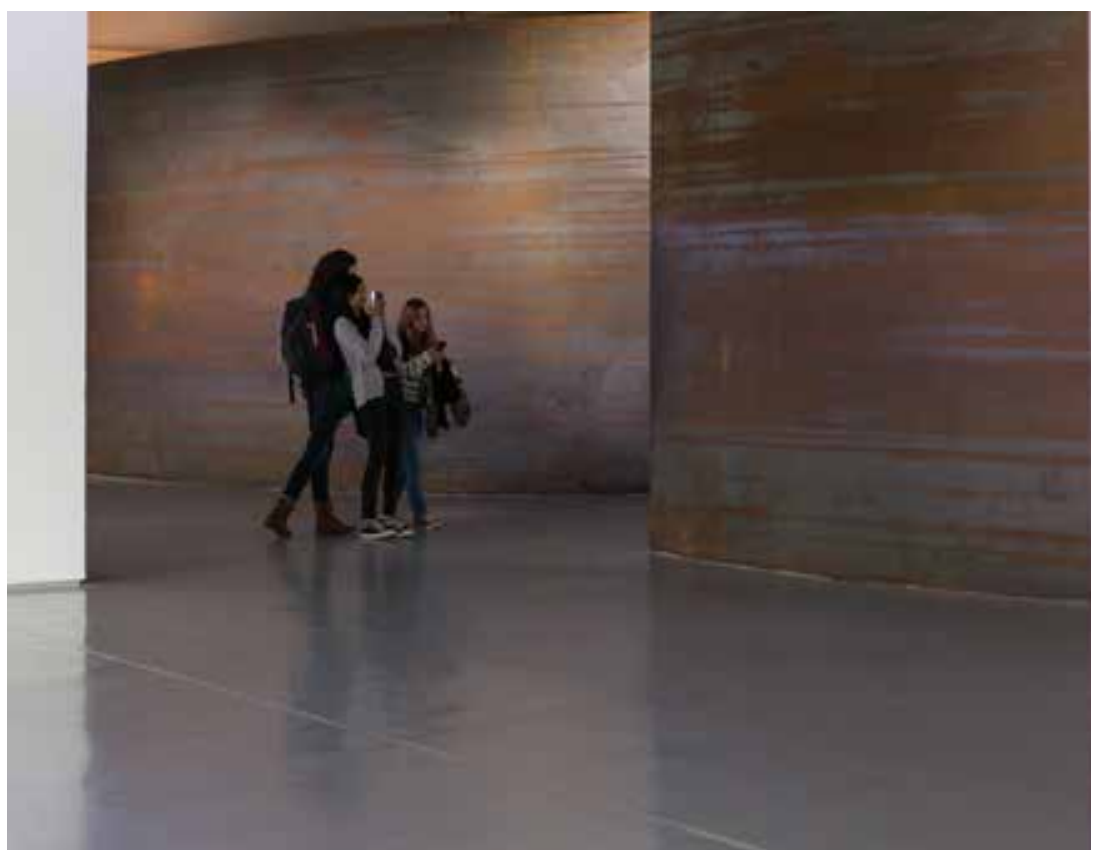

The Extended Life of Waxing Arcs

The second example is Richard Serra's site-specific installation Waxing Arcs (1980). [Figure 9] The artwork was created for Museum Boijmans Van Beuningen and followed a completely different trajectory than Tilted Arc. ${ }^{82}$ Waxing Arcs still exists, but the surroundings have changed several times and the current version is, in fact, a remake of the original. The work consists of two huge, curved plates made of Corten steel, and was specifically created for the entrance hall of the museum in commission of the then director Wim Beeren. In the course of time, the initial site specificity was challenged more than once, because the architectural surroundings and the function of the exhibition space repeatedly changed. At a certain moment, the arcs

82 The information for this case example was kindly provided by Saskia van Kampen, curator of contemporary art at the Museum Boijmans Van Beuningen, who initiated and executed the project Serra on the Move in 2014. 
marked the museum's cloakrooms; later, they gave access to the ticket office; and later still, the museum's café was placed opposite the arcs. Until May 2019, Waxing Arcs was exhibited in a separate space on the museum's ground-floor Bodon Gallery, the so-called Serra Room.

A crucial moment in the biography of Waxing Arcs was 1999, when Serra agreed to its refabrication to accommodate the artwork to the reconstruction of the museum building. The entrance of the building was relocated and equipped with a façade of concrete, steel, and glass - affecting the dimensions of the space surrounding Waxing Arcs. Two new Corten steel plates were manufactured, with a slightly different curve and measuring one metre higher; the plates were half a centimetre thicker than the originals. In addition, the suspended ceiling of the exhibition space was removed to create a more industrial look.

In terms of the triad of spatiality, the successive biographical stages show a strong mutual relationship between the spatial design of Waxing Arcs and the representational functions of its surrounding space. One can even observe a dominance of the representational space at the expense of the spatial design as originally intended by the artist. Furthermore, together with the series of new functions, the social use of the space surrounding Waxing Arcs varied, and the public's perception was influenced by those changes, not least because their trajectories along the arcs altered with each modification.

When examining the actors involved and the underlying scripts of the decision-making processes, we see a range of directors and architects who developed their own "script" for the building. Serra himself agreed to the adjustments, but in 2003, when the Serra Room was created, he stipulated that no other artworks could be exhibited next to Waxing Arcs. The only exception to this script were artworks made of light by the Minimalist artist Dan Flavin, whose artworks Serra was familiar with and which were often site-specific as well. As it turned out, the Museum Boijmans Van Beuningen could not comply with this request. The Serra Room has large dimensions, and the space is frequently needed for other exhibition purposes so that other artworks are shown in close vicinity to the arcs. ${ }^{83}$

In 2013, the museum's curator of contemporary art, Saskia Van Kampen, acknowledged that incongruences had taken place vis-à-vis the intended

83 Sometimes, Waxing Arcs has even served as a "background" for other artworks. When I visited a solo exhibition of the Dutch artist Peter Zegveld in 2013, for example, I was surprised to see one of Zegveld's lightworks projected on the orange-brownish surface of one of the Waxing Arcs. 
Figure 10 In Constant Motion: Richard Serra's 'Waxing Arcs' (2013), multimedia presentation by IJsfontein in Museum Boijmans Van Beuningen, Rotterdam (MBVB). Courtesy IJsfontein/MBVB.

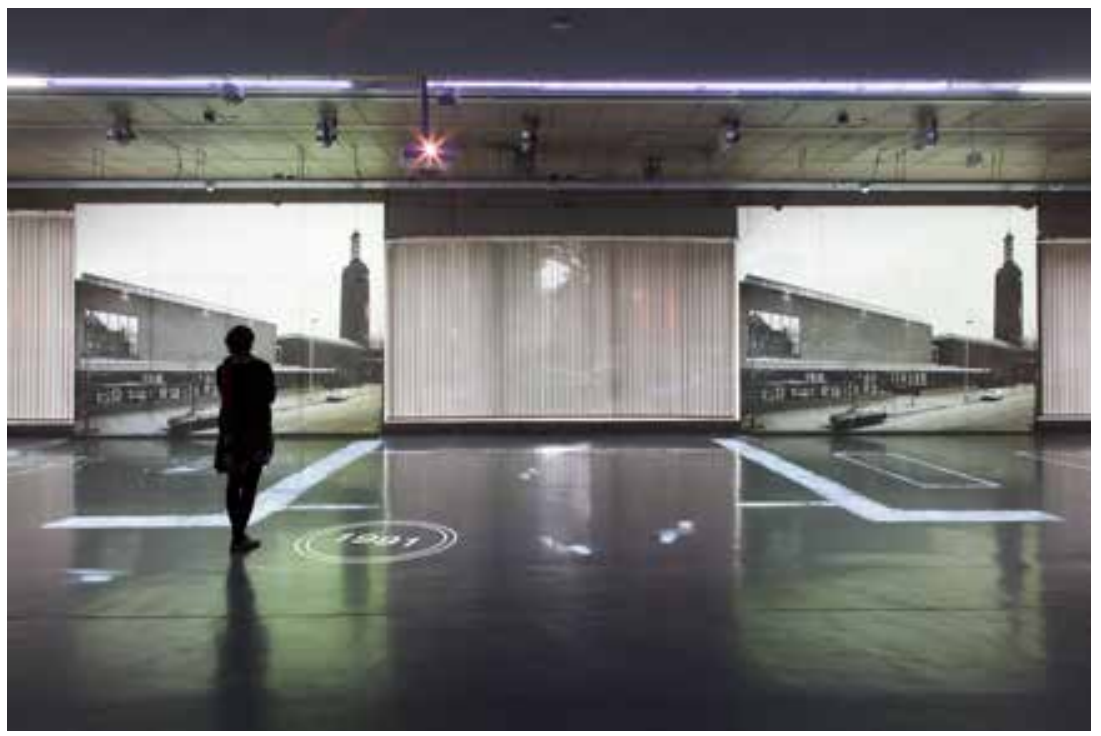

site specificity and the current "performance" of Waxing Arcs. Many shifts in the spatial network had occurred over time, as she states: "sometimes, the arcs only serve as some sort of 'obstacle' in the room." Van Kampen initiated a project to rehabilitate the work and to provide insight into the rich biography of the artwork, featuring the actors who had been involved and the underlying scripts of their decision-making. ${ }^{84}$

Focusing on the site specificity of Waxing Arcs, Van Kampen carried out in-depth research and commissioned the multimedia company IJsfontein to draw a script for a guided tour in the Serra Room, called In Constant Motion-Richard Serra's "Waxing Arcs." [Figure 10]

84 The project was part of the Stichting Behoud Moderne Kunst (Foundation for the Conservation of Contemporary Art, SBMK)'s Platform for Conservation Issues, 2013-2014. A group of museum professionals examined site-specific installation artworks made by Richard Serra in four museum collections in the Netherlands. In 2014, Saskia van Kampen realized a multimedia tour and an exhibition solely dedicated to Waxing Arcs. Additionally, the SBMK project resulted in the symposium Serra on the Move, held on 14 November 2014, https:/www.sbmk.nl/nl/ activiteiten/serraonthemove. The project was also presented at the international symposium Revisited: Site-Specificity in Recent Outdoor Sculpture, Stiftung Situation Kunst, Bochum, 26-27 February 2016. 
During the five-minute performance, the room was darkened and film fragments, photographs, and other documentary material illuminated the respective biographical stages. A voice-over explained the many twists and turns the artwork and the building had undergone. After each performance, the lights were turned off and the audience could experience the installation in daylight, just as the artist intended in $2003 .{ }^{85}$ The guided tour was on show in the museum for one year. ${ }^{86}$

What fascinates me about this performance is that the curator made the history of Waxing Arcs accessible in two ways: the virtual tour gave access to the complex network of spatial functions and its shifts over a long period of time, while at the end of the show the artist's script was followed - illuminating the "ideal" biographical stage in which the relationship between the arcs' spatial design and the gallery space was established in a room that was only separated from public space outside the building by means of the glass façade. I would like to conclude that this staging of Waxing Arcs shows a variation in possibilities to keep site-specific installation artworks alive, especially by employing virtual means of communication. Some of the options may have a documentary character, shedding light on the biographical stages of the artwork, while others may reinvigorate one spatial function of the artwork in particular and establish a renewed, spatiotemporally defined, connectivity with the exhibition site.

\subsection{Conclusion}

This chapter was dedicated to developing a conceptual model for the analysis of site-specific installation artworks. [Diagrams 1-5] The model combines two approaches, one derived from Henri Lefebvre's triad of spatiality; the other based on current notions and approaches in contemporary art conservation. The connection between the two elements of the model was first established by the argument that site-specific installation artworks move from one biographical stage to another as a result of a series of activities. Secondly, because of their performative ontology, these artworks can be analysed as performances.

85 For a full description of the project, see: https://www.boijmans.nl/en/exhibitions/richardserra-waxing-arcs_(last accessed 23 April 2021).

86 In Constant Motion: Richard Serra's "Waxing Arcs" was on show from 11 October 2014 to December 2015 . 
The benefit of the performance analogy is that it paves the way for a method to compare different iterations in a systematic way. Using the triadic model of spatial design, social space, and representational space for each manifestation of the work, the site-specific network can be described. When the artwork moves from one stage to another, it will be subjected to shifts in the spatial network due to a renewed connection of the artwork to the physical surrounding, institutional conventions, professional practices, variations in the wider sociocultural context, changed audiences, and so forth. Identifying these changes with the help of the three spatial functions sheds light on the extent and nature of the artwork's adaptability to new circumstances.

From the conservation discourse, I adopted the idea to study the artwork "in action," translated into the model as an analytical search of influential factors on the perpetuation of site-specific installations. Borrowing the notions of "script" and "actor" from conservation scholars and the actor-network theory, a "toolbox" for the model was proposed, enabling the analysis of the actors, actions, and decision-making processes leading to the reinvigoration of spatial functions, or disregarding them, in a given context and time.

The combination of the descriptive part of the model - making use of the triad of spatial functions - and the analytical part - making use of the toolbox of script and actor - should be sufficient to understand how and why site-specific installation artworks transform over time and how their perpetuation is shaped within a museum context.

In the following three main case study chapters of this book, the conceptual model will be applied to a range of site-specific installation artworks in museum collections, varying in content, form, and spatial function. Each of these case studies will emphasize a particular set of spatial functions and discuss the problem of their perpetuation.

In chapter 4 , the focus is on the functions of spatial design and social space in the site-specific installation artworks of Ernesto Neto. The example of Neto's Célula Nave. It happens in the body of time, where truth dances highlights the problem of the transition of a site-specific, temporary, and interactive installation into an artwork in a permanent collection.

In chapter 5 , the focus is on the functions of social space and representational space in Jason Rhoades's SLOTO. The Secret Life of the Onion, highlighting the problem of a commissioned site-specific installation artwork that can no longer be installed at its original location. One of the main questions in this chapter is which curatorial strategies were applied after the artist suddenly passed away. 
In chapter 6 , the focus is on the functions of spatial design and representational space of the installation Drifting Producers, created by the artists' group Flying City, as part of a sociogeographical project. The main question is if and how the museum, as the host of the only existing materialized product of this project, can reinvigorate the various dimensions of its site specificity in the past and present, within a museum context. 
